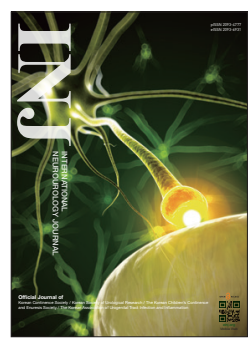

\title{
Lower Urinary Tract Symptoms in Prostate Cancer Patients Treated With Radiation Therapy: Past and Present
}

\author{
Whi-An Kwon ${ }^{1}$, Seo-Yeon Lee ${ }^{1}$, Tae Yoong Jeong ${ }^{1}$, Hong Sang Moon ${ }^{2}$ \\ ${ }^{1}$ Department of Urology, Myongji Hospital, Hanyang University College of Medicine, Goyang, Korea \\ ${ }^{2}$ Department of Urology, Hanyang University Guri Hospital, Hanyang University College of Medicine, Guri, Korea
}

\begin{abstract}
The incidence of prostate cancer $(\mathrm{PCa})$ is increasing concomitantly with population aging. Accordingly, interest in radiation therapy (RT) and the frequency of RT are also increasing. The types of RT can be broadly divided into external beam RT (EBRT), brachytherapy $(\mathrm{BT})$, and combination therapy $(\mathrm{EBRT}+\mathrm{BT})$. Lower urinary tract symptoms (LUTS) after RT for the treatment of PCa are common; however, there are few reviews on the relationship between RT and LUTS. Herein, we review the causes and incidence of LUTS, as well as the evaluation and treatment options. Because of the reported risks of RT, patients undergoing RT should be counseled regarding the challenges of treatment and informed that they may have higher failure rates than nonirradiated patients. Moreover, thorough evaluation and treatment strategies are needed to support treatment recommendations. With a review of the existing literature, this narrative article provides an overview to aid urologists in treating patients presenting with complications associated with RT for the treatment of PCa. Further research is required to provide evidence of the effectiveness and feasibility of the management approach to the care of patients with LUTS after RT for the treatment of PCa.
\end{abstract}

Keywords: Prostate cancer; Radiation therapy; Lower urinary tract symptoms

- Conflict of Interest: No potential conflict of interest relevant to this article was reported.

\section{INTRODUCTION}

Prostate cancer $(\mathrm{PCa})$ is the most common cancer in men in some countries, with more than 200,000 new cases occurring each year $[1,2]$. Most patients are diagnosed at an early, curable stage $[3,4]$, and the standard local treatment options include active surveillance, radical prostatectomy $(\mathrm{RP})$, and radiation therapy (RT). RT can be delivered as external beam RT (EBRT) and/or brachytherapy (BT) [5]. According to the SEER (Surveillance, Epidemiology, and End Result) database, the distribution of these treatment options in newly diagnosed men with PCa is as follows: RP, 36\%; EBRT, 20\%; BT, 10\%; and EBRT+BT,
$4 \%$ [6]. In cases of local disease, the 5-year survival rate approaches nearly $100 \%$ with these therapies alone or in combination. However, the adverse events associated with each treatment are diverse [7]. Because most patients are long-term survivors, quality of life - including lower urinary tract symptoms (LUTS) - is an important part of treatment decision-making.

To date, despite significant advances in RT techniques such as intensity-modulated RT, some patients treated with RT are reported to have long-term urological adverse events [8]. RT leads to tissue ischemia, fibrosis, and contraction [9], resulting in functional damage to the lower urinary tract. Urological complications may sometimes be severe, and bladder contrac-

Corresponding author: Hong Sang Moon (iD https://orcid.org/0000-0003-2101-1019 Department of Urology, Hanyang University Guri Hospital, Hanyang University College of Medicine, 153 Gyeongchun-ro, Guri 11923, Korea Email: moonuro@hanyang.ac.kr

Submitted: June 4, 2020 / Accepted after revision: August 5, 2020 
tion and loss of compliance may cause reflux uropathy and renal failure [10]. Fibrosis in the pelvis may lead to urethral stricture, and disruption of ischemic tissue may cause fistulas [11]. Extensive tissue ischemia induces poor viability of the urinary and the bowel system and may impose a substantial burden; for instance, reconstructive surgery may be required. The extent of RT-induced damage often appears to extend beyond what is expected in the field of early RT [12].

LUTS include storage, voiding, and postmicturition symptoms [13] and are a well-known adverse event of PCa RT caused by toxicity to the bladder, prostate, urethra, or a combination thereof. These complications are infrequent; nevertheless, they are difficult to treat and may require frequent hospital visits. Here, we review the causes and incidence of LUTS caused by RT for the treatment of PCa, as well as the work-up and treatment options.

\section{PREVALENCE AND CAUSES OF LUTS IN PATIENTS WITH PROSTATE CANCER AFTER RADIATION THERAPY}

\section{Urethral Stricture}

The incidence of urethral stricture varies depending on the method of RT, and has been reported to be $2 \%$ in patients receiving EBRT; $4 \%-32 \%$ in those receiving BT (depending on dose), and $11 \%$ in those receiving EBR-BT combination therapy [12]. Risk factors for urethral stricture include transurethral resection of the prostate before RT, old age, low income, and the presence of multiple comorbidities [14].

Urethral stricture after prostate primary RT predominantly occurs in the bulbomembranous urethra ( $>90 \%)$, mostly at or below the apex, despite the relatively lower exposure to radiation than in the intraprostatic urethra [6].

The effects of ionizing radiation can be classified as direct tissue damage, in the form of DNA damage, and indirect tissue damage that induces cellular apoptosis and disrupts functioning due to free radical formation in the cells. A further consequence of RT contributing to the development of urethral stenosis is vascular damage in the form of obliterative endarteritis [15].

Several radiation oncology studies have reported an increased risk of urethral stricture in patients who have undergone transurethral prostatectomy (TURP) prior to RT [16]. Studies have hypothesized that TURP prior to RT causes local damage, characterized by relative devascularization and reduced mucosal re- pair capacity [17]. Furthermore, the changes in the body after RT often remain invisible for months or years, and some studies have shown that the risk of urogenital toxicity persists 10 years after treatment [18]. Meeks et al. [19] reported that the time from RT to the occurrence of urethral stricture was between 6 and 577 months.

\section{Urinary Incontinence}

Clinically defining urinary incontinence (UI) is difficult because of its varying frequency and severity. The prevalence of UI is known to be about $30 \%$ in men over 65 years of age [20]. UI is characterized by irritable bladder (urge incontinence) and/or poor urethral sphincter function (stress incontinence) [21]. Its risk factors include aging, comorbidities, obesity, benign prostatic hyperplasia, $\mathrm{PCa}$, and treatment of PCa [3]. UI recovery after $\mathrm{RP}$ varies, with about $5 \%-30 \%$ of patients requiring a pad 1 year after surgery [22,23].

UI may also occur after EBRT and high-dose BT boost [24], with an incidence ranging from $10 \%$ to $30 \%$ [25]. The wide range of reported incidence rates is presumed to result from variance in the data caused by inconsistent definitions or other evaluation methods. After RT, UI occurs months to years later [26] and can adversely affect patients' sexual function and overall quality of life [27].

RT produces DNA strand breaks and free radicals that cause rapid cell death, leading to progressive endarteritis and hypovascular tissue. Damaged tissue is difficult to treat, and reduced blood flow eventually leads to surface necrosis and urethral fibrosis. Surgical manipulation exacerbates the problem by interfering with the blood supply and causing additional injuries of the urethral tissue and urinary sphincter [28]. The etiology of late UI following PCa RT appears to be multifactorial and is partially associated with aging and comorbidities [29]. PCa itself can compromise the integrity of the anatomical structures that maintain UI. Even men with PCa who opt for active surveillance have an increased UI risk compared to those without PCa [30].

\section{Radiation Cystitis and Fistula}

About $0 \%-9 \%$ of patients have severe urogenital toxicity after $\mathrm{RT}$, including severe radiation cystitis (RC), fistula, or urinary diversion [31]. Because severe toxicity is rare, it is not easy to determine the exact incidence. In a study of 32,465 patients who underwent PCa surgical removal and RT, patients who received RT were more likely to be readmitted, with a higher inci- 
dence of posttreatment complications and secondary malignancies than those who underwent only surgery. Among these RT patients, $0.3 \%$ had fistulas, $14.3 \%$ had hematuria, $12.1 \%$ had closure, and $4.0 \%$ had RC [31]. Studies have evaluated the functional consequences and complications associated with RT for PCa and have reported mild acute irritative urinary symptoms; however, this toxicity tends to last for months, with $75 \%$ returning to normal within a year and the remainder gradually improving in up to 3 years. Faris et al. [32] found that patients with BT seeds had a higher incidence of rectourethral fistula (RUF), whereas patients undergoing EBRT had more frequent pubovesical or urethrocutaneous fistulas. BT seeds also increased the incidence of damaged outlets, whereas combination therapy induced fusion of end-stage bladder with the occluded outlet; EBRT was more significantly associated with end-stage bladder. Patients developed symptoms after an average of 4.6 years after RT, suggesting the need for long-term follow-up, especially for the management of radiation toxicity symptoms [32].

Anterior rectal biopsy after BT was associated with RUF formation caused by poor wound healing; therefore, it is advisable to avoid it when possible [33]. Hechenbleikner et al. [34] found that $40 \%$ (169 of 416) patients with RUF had previous pelvic irradiation and/or ablation. Prior to 1997, fewer than $4 \%$ of RUF patients were exposed to radiation, whereas since $1998,50 \%$ of RUF patients have experienced induced radiation forces [35]. Pubovesical fistula is rare and can occur following the endoscopic management of bladder neck contractions after EBRT [36].

The underlying pathological physiology of RC is accompanied by advanced terminal endarteritis, leading to tissue hypoxia and terminal tissue ischemia. Necrosis and tissue slough- ing cause the deposition of fibroblasts on the ischemic tissue layer.

The processes described above are summarized in Table 1.

\section{TREATMENT OF LUTS AFTER RADIOTHERAPY FOR PROSTATE CANCER}

The treatments, discussed in detail below, are summarized in Table 2.

\section{Urethral Stricture}

Endoscopic urethral dilatation and visual internal urethrotomy (VIU) can be used to manage short urethral strictures; however, the recurrence rate is high. Although urethroplasty has a higher reported success rate, its applicability is limited by radiation damage to the normal urethra [37].

\section{Endoscopic management}

Endoscopic management, including dilatation of radiation-induced strictures and VIU, has been proposed as a first-line treatment [6]; nevertheless, it should not be recommended, especially after repeated recurrence [38]. The risk of recurrence is almost $50 \%$ or higher in patients who have undergone BT, and repeated urethral dilation and VIU often induce delays in treatment and additional fibrosis of irradiated tissues [39].

\section{Perineal excision and primary anastomosis}

Hofer et al. [40] reported that about $75 \%$ of procedures were successful and durable reconstructions were possible. The 2-year follow-up success rate increased to $85 \%$ with growing experience. Late recurrence was rare (2.7\%), and UI occurred in $7 \%-19 \%$ of cases. Staged application of artificial urinary

Table 1. Prevalence and causes of LUTS in patients with PCa after RT

\begin{tabular}{lll}
\hline Disease & \multicolumn{1}{c}{ Prevalence } & \multicolumn{1}{c}{ Causes } \\
\hline Urethral stricture & $2 \%(\mathrm{EBRT})[12]$ & - Direct tissue damage (in the form of DNA damage) \\
& $4 \%-32 \%(\mathrm{BT})[12]$ & - Indirect tissue damage that disrupts cellular apoptosis \\
& $11 \%(\mathrm{EBRT}-\mathrm{BT}$ combination) $[12]$ & \\
Urinary incontinence & $10 \%-30 \%$ (EBRT and high-dose BT boost) $[25]$ & $\begin{array}{l}\text { - Progressive endarteritis and hypovascular tissue (due to DNA strand } \\
\text { breaks and free radicals that cause rapid cell death) }\end{array}$ \\
Radiation cystitis & $4 \%[31]$ & - Tissue hypoxia and terminal tissue ischemia \\
Fistula & $0.3 \%[31]$ & - Poor wound healing (caused by RT and rectal procedures)
\end{tabular}

LUTS, lower urinary tract symptoms; PCa, prostate cancer; RT, radiotherapy; EBRT, external beam radiation therapy; BT, brachytherapy. 
Table 2. Treatment of LUTS after radiotherapy for PCa

\begin{tabular}{ll}
\hline Disease & \multicolumn{1}{c}{ Treatment } \\
\hline Urethral stricture & - Endoscopic management \\
& - Perineal excision and primary anastomosis \\
& - Urethroplasty using grafts or flaps \\
& - Management with chronic suprapubic tube \\
Urinary incontinence & - Artificial urinary sphincters (widely recommended) \\
& - Transobturator slings (not generally recommended) \\
Rectourinary fistulas & - Surgical management: transperineal, transsphincteric (Yoke-Mason), transanal, and transabdominal (open, laparoscopic, \\
& and robotic) \\
& - Conservative management: clean intermittent catheterization, low-residual diet, and surgical procedures aimed to \\
& accomplish urinary or fecal diversion (suprapubic catheter, nephrostomy, ileostomy, and colostomy) \\
& - Systemic therapies: WF10, sodium pentosan polysulfate \\
& - Hyperbaric oxygenation \\
& - Intravesical therapies: hyaluronic acid, aluminum salts, formalin, epsilon-aminocaproic acid, silver nitrate, prostaglandins, \\
& botulinum toxins, polydeoxyribonucleotides, and early placental extract \\
Radiation cystitis & - Ablative therapies: laser (yttrium-aluminum-garnet and GreenLight) or argon beam \\
& - Radiological interventions: transcatheter arterial embolization of the vesical or prostatic artery \\
& - Surgical treatment
\end{tabular}

LUTS, lower urinary tract symptoms; PCa, prostate cancer.

sphincters was the treatment of choice for these men [40]. After excision and primary anastomosis, patients' sexual function appeared unchanged and postoperative erectile dysfunction rates were similar to those reported in previous studies. In rare cases, the strictures were located proximally; abdominoperineal anastomosis can be performed if perineal access alone is insufficient for complete wound resection and reanalysis of the bladder neck or proximal urethral stub.

\section{Urethroplasty using grafts or flaps}

Although urethroplasty with grafts and flaps has been reported to have success rates of $71 \%-83 \%$ [40], there are concerns about the success rate, because tissues such as buccal mucosa grafts or genital fasciocutaneous flaps are transplanted onto the irradiated recipient tissue with poor vascularity. Therefore, a combination of buccal mucosa grafts and gracilis muscle flaps can be considered when tissue transfer is required.

\section{Management with a chronic suprapubic tube}

Urinary diversion including cystostomy in patients with urethral stricture after RT may be performed for the dual purposes of urethral rest and long-term management of appropriately consulted patients. Terlecki et al. [41]. found that urethral rest allowed the recovery of urethral tissue and helped to determine the severity of stricture and the extent of involvement in surgical planning. At some institutions, after undergoing urethral rest for 2-3 months, chronic suprapubic drainage or reconstruction surgery is performed after sufficient consultation and consideration of the medical status of the patient [38].

\section{Urinary Incontinence}

After treatment of urethral stricture following RT, the wellknown complication of UI is relatively rare; nevertheless, it occasionally requires additional evaluation and treatment. Transobturator slings, which are often used to treat stress UI in women, do not show good results in RT-induced UI and are not generally recommended [42]. Consequently, artificial urinary sphincters are widely recommended. However, artificial urinary sphincters are known to have a higher erosion rate $(6 \%-13 \%)$ in irradiated patients than in nonirradiated patients (4\%). Some studies reported that $3.5-\mathrm{cm}$ cuffs are associated with a higher risk of RT-induced incontinence treatment failure than cuffs of $4.0 \mathrm{~cm}$ or larger [43]; however, recent studies have shown that there is no such difference [44]. It was also proposed that the transcorporal artificial urinary sphincters could have improved results with the placement of cuffs larger than 
$3.5 \mathrm{~cm}$ in high-risk patients undergoing radiation and multiple previous urethral manipulations; however, opposite results have been reported in recent research [45].

\section{Rectourinary Fistulas}

Urinary fistula is the most difficult RT-related urological complication to manage and may be the most serious of all the complications that occur [46]. There is no standardized behavioral protocol for subjects because of the rarity and complexity of RUF, and most published studies are retrospective experiences from single institutions [47]. Few large studies have compared the results of different approaches to identify possible factors associated with surgical success or failure, and no prospective studies of this issue have been conducted [48]. One of the most important points is the classification of RUF as simple or complex. RUF is considered complex if the fistula size is $\geq 2$ $\mathrm{cm}$, and if there is urethral stricture, bladder neck sclerosis, or ischemic tissue. In contrast, a fistula is considered simple if it occurs secondary to surgical trauma to previously healthy tissue [49].

\section{Surgical management}

For complex RUF, a surgical approach is required. The ultimate goal of RUF treatment is fistula closure and recovery of bowel and bladder function [50]. Numerous approaches have been described in the literature, 4 of which are major (transperineal, transsphincteric [Yoke-Mason], transanal, and transabdominal [open, laparoscopic, and robotic]) [51].

\section{Conservative management}

Conservative management refers to procedures that exclude surgical treatment, including clean intermittent catheterization, a low-residual diet, and surgical procedures aimed to accomplish urinary or fecal diversion (suprapubic catheter, nephrostomy, ileostomy, and colostomy) [52]. The indications for conservative management are not well defined. In general, complete and spontaneous closure of RUF is rare; however, simple fistulas that have not yet developed the epithelium of the fistula tract are capable of spontaneous closure within the first 12 weeks [49]. Nonetheless, the spontaneous closure of complex RUFs is an exception, especially in irradiated tissue; therefore, conservative methods should not be used for these patients. According to the literature, the success rate of maintenance of simple RUF was from $14 \%-100 \%$ [53].

\section{Radiation Cystitis} Systemic therapies

WF10 is an intravenous preparation produced from the drug OXO K993, which is also known as tetrachlorodecaoxygen. Its mechanism of action is based on RC being a chronic inflammatory condition. WF10 induces innate immunity and stimulates cellular defense mechanisms through the effects of natural killer cells, cytotoxic T-lymphocytes, and modifications of the monocyte-macrophage system to rapidly reduce inflammation.

Sodium pentosan polysulfate is a synthetic sulfated polysaccharide that has been used to reduce urinary tract permeability by replacing defective glycosaminoglycans. Sandhu et al. [54] evaluated the efficacy of sodium pentosan polysulfate (100 mg 3 times daily) to treat radiation-induced hemorrhagic cystitis (HC) in 60 patients. Overall, 51 patients were followed up, of whom 21 patients with a partial response underwent gradual reductions of the dose with a maintenance dose of $100 \mathrm{mg}$, and 10 patients showed a complete response.

\section{Hyperbaric oxygenation}

Hyperbaric oxygenation (HBO) therapy increases oxygen transfer to tissues by increasing the amount of oxygen dissolved in plasma to induce and restore normal compensation of granulocytes and fibroblasts, resulting in increased capillary density. $\mathrm{HBO}$ induces neo-angiogenesis with a recovery of $\leq 80 \%$ of capillary density [55]. Complete resolution of hematuria has been reported in $34 \%-87.5 \%$ of patients [56].

\section{Intravesical therapies}

Response rates for intravesical therapy typically range from $60 \%$ to $90 \%$ [57,58]. Formalin induces occlusive fixation of the telangiectatic and friable microvasculature by precipitating cellular proteins within the epithelial layer. Contemporary evidence for the use of formalin is poor, with fatal complications reported in $2 \%-4 \%$ of cases [59]. Therefore, formalin is recommended only in the case of intractable $\mathrm{HC}$ requiring urinary tract diversion [60]. The mechanism of action of aluminum salt (generally potassium or ammonium aluminum sulfate) is to precipitate proteins on the cell surface. Aluminum salts are not as effective as formalin; however, they produce fewer side effects and, therefore, might be considered if other early conservative therapies fail [61].

More recent intravesical therapies aim to supplement the protective glycosaminoglycan layer to reduce host urinary exposure of basal epithelial cells. Hyaluronic acid is a major mu- 
copolysaccharide that can be injected into the bladder and has immunomodulatory properties that improve connective tissue healing [62]. Epsilon-aminocaproic acid inhibits fibrin degradation by urokinase in exposed telangiectatic vessels exposed from the bladder after irradiation [63]. Other intravesical agents include silver nitrate, prostaglandins, botulinum toxins, polydeoxyribonucleotides, and early placental extract. However, these agents have been reported to have a limited remission rate [62]

\section{Ablative therapies}

Laser (yttrium-aluminum-garnet [YAG] and GreenLight) therapy or argon beam therapy has a complete remission result of about $75 \%-97 \%$, and has the clinical advantage of immediate control of bleeding $[64,65]$. The GreenLight laser ablates blood vessels through a mechanism that selectively absorbs green light by intravascular oxyhemoglobin, resulting in relatively little damage to surrounding tissues [65]. Conversely, YAG lasers are non-selective and increase the risk of bladder perforation due to sloughing of necrotic tissue after treatment [66]. Argon ablation has the advantage that the current follows the path of least resistance and can prevent perforation by migrating to the adjacent tissue after coagulation is achieved. Furthermore, the cutting depth can be changed by adjusting the power supply and gas flow rate [64].

\section{Radiological intervention}

Transcatheter arterial embolization of the vesical or prostatic artery may be considered for patients with failed treatment methods and patients considered unfit for cystectomy. Although there is limited evidence of arterial embolism for the management of HC, technical success has been reported in $90 \%-100 \%$ of patients (clinical success in $70 \%-100 \%$ ) when vesical or prostatic arteries can be identified [67].

\section{Surgical treatment}

Urinary diversion with or without cystectomy may be performed if all other noninvasive treatment methods fail. A study of 21 patients undergoing cystectomy and urinary diversion for intractable HC showed that $42 \%$ of patients had Clavien-Dindo classification grade III or higher complications during the perioperative period; the 90 -day mortality rate was $16 \%$ and the overall 1-year survival rate was $84 \%$ [68].

\section{CONCLUSIONS}

Patients undergoing RT for PCa-induced LUTS are a challenging group characterized by diverse symptoms. LUTS may originate from a number of etiologies, including urethral stricture, $\mathrm{UI}, \mathrm{RC}$, and fistulas. Thorough evaluation and treatment strategies are needed to support treatment recommendations. Patients should be counseled that treatment is often challenging and they may have higher failure rates than nonirradiated patients.

Clinicians need to understand the concepts of these diseases and consider patients' characteristics to balance the effectiveness and safety of treatment. Due to the relatively small number of existing studies, further research is needed in this field.

\section{ORCID}

$\begin{array}{ll}\text { Whi-An Kwon } & 0000-0002-7833-5981 \\ \text { Seo-Yeon Lee } & 0000-0003-3397-5595 \\ \text { Tae Yoong Jeong } & 0000-0003-3408-6853 \\ \text { Hong Sang Moon } & 0000-0003-2101-1019\end{array}$

\section{AUTHOR CONTRIBUTION STATEMENT}

- Conceptualization: HSM

- Formal analysis: WK, SL, TYJ, HSM

- Methodology: WK, TYJ

- Writing-original draft: $W K$

-Writing-review \& editing: WK, SL, TYJ, HSM

\section{REFERENCES}

1. Mohler JL, Kantoff PW, Armstrong AJ, Bahnson RR, Cohen M, D’Amico AV, et al. Prostate cancer, version 2.2014. J Natl Compr Canc Netw 2014;12:686-718.

2. Kim WT, Yun SJ, Kim WJ. For Physicians managing voiding dysfunction, improving the detection rate of early prostate cancer and discrimination from benign prostatic hyperplasia, in a molecular biomarker aspects. Int Neurourol J 2019;23:5-12.

3. Heidenreich A, Bastian PJ, Bellmunt J, Bolla M, Joniau S, van der Kwast T, et al. EAU guidelines on prostate cancer. part 1: screening, diagnosis, and local treatment with curative intent-update 2013. Eur Urol 2014;65:124-37.

4. Ha YS, Yoo ES. Artificial urinary sphincter for postradical prostatectomy urinary incontinence - is it the best option? Int Neurourol 
J 2019;23:265-76.

5. Heidenreich A, Bastian PJ, Bellmunt J, Bolla M, Joniau S, van der Kwast T, et al. EAU guidelines on prostate cancer. Part II: treatment of advanced, relapsing, and castration-resistant prostate cancer. Eur Urol 2014;65:467-79.

6. Herschorn S, Elliott S, Coburn M, Wessells H, Zinman L. SIU/ ICUD consultation on urethral strictures: posterior urethral stenosis after treatment of prostate cancer. Urology 2014;83:S59-70.

7. Hudson SV, O'Malley DM, Miller SM. Achieving optimal delivery of follow-up care for prostate cancer survivors: improving patient outcomes. Patient Relat Outcome Meas 2015;6:75-90.

8. Viswanathan AN, Yorke ED, Marks LB, Eifel PJ, Shipley WU. Radiation dose-volume effects of the urinary bladder. Int J Radiat Oncol Biol Phys 2010;76:S116-22.

9. Shibamoto Y, Tsuchida E, Seki K, Oya N, Hasegawa M, Toda Y, et al. Primary central nervous system lymphoma in Japan 1995-1999: changes from the preceding 10 years. J Cancer Res Clin Oncol 2004;130:351-6.

10. Zoubek J, McGuire EJ, Noll F, DeLancey JO. The late occurrence of urinary tract damage in patients successfully treated by radiotherapy for cervical carcinoma. J Urol 1989;141:1347-9.

11. Farquharson DI, Shingleton HM, Soong SJ, Sanford SP, Levy DS, Hatch KD. The adverse effects of cervical cancer treatment on bladder function. Gynecol Oncol 1987;27:15-23.

12. Morris KA, Haboubi NY. Pelvic radiation therapy: between delight and disaster. World J Gastrointest Surg 2015;7:279-88.

13. Abrams P, Cardozo L, Fall M, Griffiths D, Rosier P, Ulmsten U, et al. The standardisation of terminology of lower urinary tract function: report from the Standardisation Sub-committee of the International Continence Society. Neurourol Urodyn 2002;21:167-78.

14. Awad MA, Gaither TW, Osterberg EC, Murphy GP, Baradaran N, Breyer BN. Prostate cancer radiation and urethral strictures: a systematic review and meta-analysis. Prostate Cancer Prostatic Dis 2018;21:168-74.

15. Devalia HL, Mansfield L. Radiotherapy and wound healing. Int Wound J 2008;5:40-4.

16. Ohri N, Dicker AP, Showalter TN. Late toxicity rates following definitive radiotherapy for prostate cancer. Can J Urol 2012;19:637380.

17. Grechenkov A, Sukhanov R, Bezrukov E, Butnaru D, Barbagli G, Vasyutin I, et al. Risk factors for urethral stricture and/or bladder neck contracture after monopolar transurethral resection of the prostate for benign prostatic hyperplasia. Urologia 2018;85:150-7.

18. Kim S, Moore DF, Shih W, Lin Y, Li H, Shao YH, et al. Severe genitourinary toxicity following radiation therapy for prostate cancer- -how long does it last? J Urol 2013;189:116-21.

19. Meeks JJ, Brandes SB, Morey AF, Thom M, Mehdiratta N, Valadez C, et al. Urethroplasty for radiotherapy induced bulbomembranous strictures: a multi-institutional experience. J Urol 2011;185:1761-5.

20. Anger JT, Saigal CS, Stothers L, Thom DH, Rodríguez LV, Litwin MS. The prevalence of urinary incontinence among community dwelling men: results from the National Health and Nutrition Examination survey. J Urol 2006;176:2103-8; discussion 8.

21. Fong E, Nitti VW. Urinary incontinence. Prim Care 2010;37:599612 , ix.

22. Tienza A, Graham PL, Robles JE, Diez-Caballero F, Rosell D, Pascual JI, et al. Daily pad usage versus the international consultation on incontinence questionnaire form for the continence assessment following radical prostatectomy. Int Neurourol J 2020;24:156-62.

23. Huh JS, Kim YJ, Kim SD, Park KK. The effectiveness of cystography-measured bladder neck elevation at predicting the return of continence after robot-assisted radical prostatectomy. Int Neurourol J 2019;23:234-9.

24. Gomez-Iturriaga A, Casquero F, Pijoan JI, Minguez P, Espinosa JM, Irasarri A, et al. Health-related-quality-of-life and toxicity after single fraction $19 \mathrm{~Gy}$ high-dose-rate prostate brachytherapy: phase II trial. Radiother Oncol 2018;126:278-82.

25. Hauswald H, Kamrava MR, Fallon JM, Wang PC, Park SJ, Van T, et al. High-dose-rate monotherapy for localized prostate cancer: 10year results. Int J Radiat Oncol Biol Phys 2016;94:667-74.

26. Moon DH, Basak RS, Usinger DS, Dickerson GA, Morris DE, Perman $\mathrm{M}$, et al. Patient-reported quality of life following stereotactic body radiotherapy and conventionally fractionated external beam radiotherapy compared with active surveillance among men with localized prostate cancer. Eur Urol 2019;76:391-7.

27. Bedretdinova D, Fritel X, Zins M, Ringa V. The effect of urinary incontinence on health-related quality of life: is it similar in men and women? Urology 2016;91:83-9.

28. Mock S, Leapman M, Stock RG, Hall SJ, Stone NN. Risk of urinary incontinence following post-brachytherapy transurethral resection of the prostate and correlation with clinical and treatment parameters. J Urol 2013;190:1805-10.

29. Resnick MJ, Koyama T, Fan KH, Albertsen PC, Goodman M, Hamilton AS, et al. Long-term functional outcomes after treatment for localized prostate cancer. N Engl J Med 2013;368:436-45.

30. Ansmann L, Winter N, Ernstmann N, Heidenreich A, Weissbach L, Herden J. Health-related quality of life in active surveillance and radical prostatectomy for low-risk prostate cancer: a prospective observational study (HAROW-Hormonal therapy, Active Surveillance, Radiation, Operation, Watchful Waiting). BJU Int 2018;122: 
401-10.

31. Nam RK, Cheung P, Herschorn S, Saskin R, Su J, Klotz LH, et al. Incidence of complications other than urinary incontinence or erectile dysfunction after radical prostatectomy or radiotherapy for prostate cancer: a population-based cohort study. Lancet Oncol 2014;15:223-31.

32. Faris SF, Milam DF, Dmochowski RR, Kaufman MR. Urinary diversions after radiation for prostate cancer: indications and treatment. Urology 2014;84:702-6.

33. Hanna JM, Peterson AC, Mantyh C. Rectourethral fistulas in the cancer survivor. Curr Opin Urol 2014;24:382-8.

34. Hechenbleikner EM, Buckley JC, Wick EC. Acquired rectourethral fistulas in adults: a systematic review of surgical repair techniques and outcomes. Dis Colon Rectum 2013;56:374-83.

35. Harris CR, McAninch JW, Mundy AR, Zinman LN, Jordan GH, Andrich D, et al. Rectourethral fistulas secondary to prostate cancer treatment: management and outcomes from a multi-institutional combined experience. J Urol 2017;197:191-4.

36. Matsushita K, Ginsburg L, Mian BM, De E, Chughtai BI, Bernstein $\mathrm{M}$, et al. Pubovesical fistula: a rare complication after treatment of prostate cancer. Urology 2012;80:446-51.

37. Rosenbaum CM, Engel O, Fisch M, Kluth LA. Urethral stricture after radiation therapy. Urologe A 2017;56:306-12.

38. Hofer MD, Liu JS, Morey AF. Treatment of radiation-induced urethral strictures. Urol Clin North Am 2017;44:87-92.

39. Sullivan L, Williams SG, Tai KH, Foroudi F, Cleeve L, Duchesne GM. Urethral stricture following high dose rate brachytherapy for prostate cancer. Radiother Oncol 2009;91:232-6.

40. Hofer MD, Zhao LC, Morey AF, Scott JF, Chang AJ, Brandes SB, et al. Outcomes after urethroplasty for radiotherapy induced bulbomembranous urethral stricture disease. J Urol 2014;191:1307-12.

41. Terlecki RP, Steele MC, Valadez C, Morey AF. Urethral rest: role and rationale in preparation for anterior urethroplasty. Urology 2011;77:1477-81.

42. Torrey R, Rajeshuni N, Ruel N, Muldrew S, Chan K. Radiation history affects continence outcomes after advance transobturator sling placement in patients with post-prostatectomy incontinence. Urology 2013;82:713-7.

43. Simhan J, Morey AF, Singla N, Tausch TJ, Scott JF, Lemack GE, et al. $3.5 \mathrm{~cm}$ artificial urinary sphincter cuff erosion occurs predominantly in irradiated patients. J Urol 2015;193:593-7.

44. McKibben MJ, Shakir N, Fuchs JS, Scott JM, Morey AF. Erosion rates of 3.5-cm artificial urinary sphincter cuffs are similar to larger cuffs. BJU Int 2019;123:335-41.

45. Davenport MT, Akhtar AM, Shakir NA, Baumgarten AS, Yi YA,
Bergeson RL, et al. Comparison of $3.5 \mathrm{~cm}$ and transcorporal cuffs in high-risk artificial urinary sphincter populations. Transl Androl Urol 2020;9:62-6.

46. Mundy AR, Andrich DE. Posterior urethral complications of the treatment of prostate cancer. BJU Int 2012;110:304-25.

47. Andrews EJ, Royce P, Farmer KC. Transanal endoscopic microsurgery repair of rectourethral fistula after high-intensity focused ultrasound ablation of prostate cancer. Colorectal Dis 2011;13:342-3.

48. Keller DS, Aboseif SR, Lesser T, Abbass MA, Tsay AT, Abbas MA. Algorithm-based multidisciplinary treatment approach for rectourethral fistula. Int J Colorectal Dis 2015;30:631-8.

49. Ramírez-Martín D, Jara-Rascón J, Renedo-Villar T, HernándezFernández C, Lledó-García E. Rectourethral Fistula Management. Curr Urol Rep 2016;17:22.

50. Tran H, Flannigan R, Rapoport D. Transperineal approach to complex rectourinary fistulae. Can Urol Assoc J 2015;9:E916-20.

51. Chen S, Gao R, Li H, Wang K. Management of acquired rectourethral fistulas in adults. Asian J Urol 2018;5:149-54.

52. Thompson IM, Marx AC. Conservative therapy of rectourethral fistula: five-year follow-up. Urology 1990;35:533-6.

53. Venkatesan K, Zacharakis E, Andrich DE, Mundy AR. Conservative management of urorectal fistulae. Urology 2013;81:1352-6.

54. Sandhu SS, Goldstraw M, Woodhouse CR. The management of haemorrhagic cystitis with sodium pentosan polysulphate. BJU Int 2004;94:845-7.

55. Muhonen A, Haaparanta M, Grönroos T, Bergman J, Knuuti J, Hinkka S, et al. Osteoblastic activity and neoangiogenesis in distracted bone of irradiated rabbit mandible with or without hyperbaric oxygen treatment. Int J Oral Maxillofac Surg 2004;33:173-8.

56. Degener S, Pohle A, Strelow H, Mathers MJ, Zumbé J, Roth S, et al. Long-term experience of hyperbaric oxygen therapy for refractory radio- or chemotherapy-induced haemorrhagic cystitis. BMC Urol 2015;15:38.

57. Ziegelmann MJ, Boorjian SA, Joyce DD, Montgomery BD, Linder BJ. Intravesical formalin for hemorrhagic cystitis: a contemporary cohort. Can Urol Assoc J 2017;11:E79-82.

58. Westerman ME, Boorjian SA, Linder BJ. Safety and efficacy of intravesical alum for intractable hemorrhagic cystitis: a contemporary evaluation. Int Braz J Urol 2016;42:1144-9.

59. Lojanapiwat B, Sripralakrit S, Soonthornphan S, Wudhikarn S. Intravesicle formalin instillation with a modified technique for controlling haemorrhage secondary to radiation cystitis. Asian J Surg 2002;25:232-5.

60. Denton AS, Clarke NW, Maher EJ. Non-surgical interventions for late radiation cystitis in patients who have received radical radio- 
therapy to the pelvis. Cochrane Database Syst Rev 2002;2002: Cd001773.

61. Smit SG, Heyns CF. Management of radiation cystitis. Nat Rev Urol 2010;7:206-14.

62. Browne C, Davis NF, Mac Craith E, Lennon GM, Mulvin DW, Quinlan DM, et al. A narrative review on the pathophysiology and management for radiation cystitis. Adv Urol 2015;2015:346812.

63. Singh I, Laungani GB. Intravesical epsilon aminocaproic acid in management of intractable bladder hemorrhage. Urology 1992; 40:227-9.

64. Wines MP, Lynch WD. A new minimally invasive technique for treating radiation cystitis: the argon-beam coagulator. BJU Int 2006;98:610-2.

65. Talab SS, McDougal WS, Wu CL, Tabatabaei S. Mucosa-sparing,
KTP laser coagulation of submucosal telangiectatic vessels in patients with radiation-induced cystitis: a novel approach. Urology 2014;84:478-83.

66. Hoffman RM, MacDonald R, Slaton JW, Wilt TJ. Laser prostatectomy versus transurethral resection for treating benign prostatic obstruction: a systematic review. J Urol 2003;169:210-5.

67. Loffroy R, Pottecher P, Cherblanc V, Favelier S, Estivalet L, Koutlidis $\mathrm{N}$, et al. Current role of transcatheter arterial embolization for bladder and prostate hemorrhage. Diagn Interv Imaging 2014;95: 1027-34.

68. Linder BJ, Tarrell RF, Boorjian SA. Cystectomy for refractory hemorrhagic cystitis: contemporary etiology, presentation and outcomes. J Urol 2014;192:1687-92. 